\title{
Endocrinization of FGF1 produces a neomorphic and potent insulin sensitizer
}

\author{
Jae Myoung Suh ${ }^{1, \dagger}$, Johan W. Jonker ${ }^{3, \dagger}$, Maryam Ahmadian ${ }^{1}$, Regina Goetz ${ }^{6}$, Denise \\ Lackey $^{5}$, Olivia Osborn ${ }^{5}$, Zifeng Huang ${ }^{6}$, Weilin Liu ${ }^{3}$, Eiji Yoshihara ${ }^{1}$, Theo van Dijk ${ }^{3}$, Rick \\ Havinga $^{3}$, Weiwei Fan ${ }^{1}$, Yun-Qiang Yin ${ }^{1}$, Ruth T. Yu ${ }^{1}$, Christopher Liddle ${ }^{4}$, Annette R. \\ Atkins $^{1}$, Jerrold M. Olefsky ${ }^{5}$, Moosa Mohammadi ${ }^{6}$, Michael Downes ${ }^{1,{ }^{*}}$, and Ronald M. \\ Evans $^{1,2,{ }^{*}}$
}

${ }^{1}$ GeneExpression Laboratory, Salk Institute for Biological Studies, La Jolla, California, USA ${ }^{2}$ Howard Hughes Medical Institute, Salk Institute for Biological Studies, La Jolla, California, USA ${ }^{3}$ Center for Liver, Digestive and Metabolic Diseases, Departments of Pediatrics and Laboratory Medicine, University of Groningen, University Medical Center Groningen, Hanzeplein 1, $9713 \mathrm{GZ}$ Groningen, The Netherlands ${ }^{4}$ The Storr Liver Unit, Westmead Millennium Institute and University of Sydney, Westmead Hospital, Westmead, New South Wales 2145, Australia ${ }^{5}$ Department of Medicine, Division of Endocrinology and Metabolism, University of California at San Diego, La Jolla, California 92093, USA ${ }^{6}$ Department of Pharmacology, New York University School of Medicine, New York, New York 10016, USA

\begin{abstract}
FGF1 is an autocrine/paracrine regulator whose binding to heparan sulfate proteoglycans effectively precludes its circulation ${ }^{1,2}$. Though known as a mitogenic factor, FGF1 knockout mice develop insulin resistance when stressed by a high fat diet, suggesting a potential role in nutrient homeostasis ${ }^{3,4}$. Here we show that parenteral delivery of a single dose of recombinant FGF1 (rFGF1) results in potent, insulin-dependent glucose lowering in diabetic mice that is dosedependent, but does not lead to hypoglycemia. Chronic pharmacological rFGF1 treatment increases insulin-dependent glucose uptake in skeletal muscle and suppresses hepatic glucose production to achieve whole-body insulin sensitization. The sustained glucose lowering and insulin sensitization attributed to rFGF1 are not accompanied by the side effects of weight gain, liver steatosis and bone loss associated with current insulin sensitizing therapies. Furthermore, we demonstrate that the glucose lowering activity of FGF1 can be dissociated from its mitogenic
\end{abstract}

\footnotetext{
Users may view, print, copy, and download text and data-mine the content in such documents, for the purposes of academic research, subject always to the full Conditions of use:http://www.nature.com/authors/editorial_policies/license.html\#terms

"Correspondence and requests for materials should be addressed to R.M.E. (evans@ salk.edu) or M.D. (downes@ salk.edu).

†These authors contributed equally to this work

Author Contributions J.M.S, J.W.J, M.D. and R.M.E. designed and supervised the research. J.M.S., J.W.J., M.A., R.G., D.L., O.O., Z.H., W.L., E.Y., T.H.D., R.H., W.F., Y.-Q.Y., A.R.A., performed research. J.M.S., J.W.J., M.A., R.T.Y., C.L., A.R.A., J.M.O., M.M., M.D. and R.M.E. analysed data. J.M.S., J.W.J., M.A., R.G., A.R.A., M.D. and R.M.E. wrote the manuscript.

Reprints and permissions information is available at www.nature.com/reprints.

The authors declare no competing financial interests.

Readers are welcome to comment on the online version of this article at www.nature.com/nature.
} 
activity and is mediated predominantly via FGF receptor 1 (FGFR1) signaling. In summary, we have uncovered an unexpected, neomorphic insulin sensitizing action for exogenous nonmitogenic human FGF1 with therapeutic potential for treatment of insulin resistance and type 2 diabetes.

The increased prevalence of obesity, insulin resistance and the associated incidence of difficult-to-manage type 2 diabetes have become world-wide public health problems as well as a financial burden for the health care system, emphasizing the urgent need for improved insulin sensitizing therapies. Thiazolidinediones (TZDs) are highly effective oral medications for type 2 diabetes that act through the nuclear receptor peroxisome proliferator activated receptor gamma (PPAR $\gamma$ ) to control networks of genes involved in adipogenesis, lipid metabolism and insulin sensitization. However, the unique sensitization benefits of TZDs are menaced by detrimental side-effects including weight gain, bone loss and congestive heart failure, suggesting that targeting downstream effectors of PPAR $\gamma$ may evoke fewer side effects yet retain insulin sensitizing potential ${ }^{5}$. In this regard, FGF21, a member of the endocrine FGF subfamily and a PPAR $\gamma$ target gene in adipose tissue, has been identified as an effective glucose-lowering agent in rodents 6,7 . Recently, FGF1, the prototype of the FGF family of proteins, has emerged as an adipose-specific PPAR $\gamma$ target gene and $F g f l$ knockout mice exhibit an aggressive insulin-resistant phenotype when stressed by a high fat diet ${ }^{3,4}$. The affinity of FGF1 for heparan sulfate proteoglycans (HSPGs) results in autocrine/paracrine signaling and limited serum exposure, distinguishing it from the endocrine FGFs, which include FGF2 ${ }^{1,2,8,9}$. These studies, combined with those demonstrating that FGF receptor agonist antibodies modulate glucose homeostasis 10 raised the question as to whether endocrinization of the non-endocrine FGF1 could elicit glucose-lowering effects.

To explore its therapeutic potential, recombinant murine FGF1 (rFGF1) was injected subcutaneously (subQ) into genetically-induced (ob/ob and $\mathrm{db} / \mathrm{db}$ ) as well as diet-induced obese (DIO) insulin resistant mice. Surprisingly, a single injection of $0.5 \mathrm{mg} / \mathrm{kg}$ rFGF1 was sufficient to attain normoglycemia in the severely hyperglycemic ob/ob mice (Fig. 1a). Maximal glucose lowering was achieved within 18-24 hours and sustained effects observed for more than 48 hours. Moreover, this effect was dose-dependent, but even at the maximal dose $(2.0 \mathrm{mg} / \mathrm{kg})$ did not result in hypoglycemia (Fig. $1 \mathrm{~b}$ and data not shown). Potent glucose lowering was observed in both $\mathrm{db} / \mathrm{db}$ and DIO mouse models, and rFGF1 was effective when delivered either intraperitoneally (i.p.) or intravenously (i.v.) in ob/ob mice, independent of exogenous heparin (Fig. 1c-d, Extended Data Fig. 1a, b, c). Notably, rFGF1 had no effect on blood glucose or insulin levels in normoglycemic chow-fed mice (Fig. 1e, Extended Data Fig. 1d, e). Consistent with the known feeding effects of FGF1 ${ }^{11-13}$, we observed a transient suppression of food intake that correlated with a temporary reduction in body weight (Extended Data Fig. 1f-i and data not shown). However, rFGF1 injection similarly reduced glucose levels under fasting conditions, dissociating the glucose lowering effects of rFGF1 from its effect on food intake (Fig. 1f). FGF1 is considered the universal FGF receptor (FGFR) ligand in its ability to bind and activate each of the alternatively spliced forms of the four tyrosine kinase FGF receptors (FGFRs 1-4), while other members of the FGF superfamily demonstrate receptor specificity ${ }^{1}$. To determine whether other 
autocrine/paracrine FGFs have similar blood glucose lowering activity when given pharmacologically, we tested a selection of FGFs with specificities covering all 7 FGFR receptors. Remarkably, FGF1 appears unique in its ability to lower blood glucose as FGF2, FGF9, and FGF10 failed to do so (Fig. 1g). Furthermore, recombinant human FGF1 (hFGF1) was similarly able to normalize blood glucose in diabetic mice, suggesting an evolutionarily conserved pathway (Fig. 1h).

The pronounced glucose-lowering efficacy of a single injection of rFGF1 led us to investigate the effects of serial injections. Ob/ob mice injected with $0.5 \mathrm{mg} / \mathrm{kg}$ every other day for 35 days (chronic treatment) did not develop any apparent resistance to rFGF1, exhibiting sustained glucose lowering with minimal changes in body weight or composition (Fig. 2a, b, Extended Data Fig. 2a, b). A similar glucose lowering effect was also seen in pair-fed ob/ob mice, indicating that the transient reduction in food intake upon chronic rFGF1 treatment does not account for the beneficial glucose lowering effects (Extended Data Fig. 2c, d). The fasting blood glucose levels of chronically rFGF1 treated ob/ob mice were 50\% lower than PBS treated control mice, and remained lower throughout the glucose tolerance test (GTT) with a coincident decrease in insulin levels. Furthermore, rFGF1 treated mice displayed a marked improvement in insulin sensitivity as measured by an insulin tolerance test (ITT) (Fig. 2c-e). While there was no significant effect on serum free fatty acids, cholesterol and triglyceride levels (Extended Data Table 1, Extended Data Fig. 2e, f), chronic rFGF1 treatment decreased hepatic steatosis and increased liver glycogen content, as shown histologically and by quantitative analyses (Fig. 2f-h). No significant changes were detected in serum metabolic hormone levels (Extended Data Fig. 2g). Furthermore, chronic rFGF1 treatment of DIO mice, which more closely models the majority of human type 2 diabetes, also resulted in pronounced and sustained lowering of blood glucose levels (Fig. 2i) as well as in increased insulin sensitization, measured by GTT and ITT (Fig. 2j, k). Notably, these beneficial effects in DIO mice were observed without significant changes in body weight, organ weights, and feeding trends (Extended Data Fig. $2 h-j)$.

The potent and rapid normalization of blood glucose by parenteral rFGF1 led us to investigate potential insulin secretagogue or insulin-mimetic activities of rFGF1. rFGF1 injection had no significant effect on glucose-stimulated insulin secretion in isolated pancreatic islets and did not increase serum insulin levels under basal conditions or during a GTT, indicating exogenous FGF1 does not stimulate pancreatic $\beta$-cell insulin release both ex vivo and in vivo (Fig 2d, Extended Data Fig. 3a-c). Next, we tested rFGF1 efficacy in mice rendered diabetic by streptozotocin-induced destruction of insulin-producing $\beta$-cells. In this diabetic mouse model (STZ mice), rFGF1 alone failed to lower blood glucose levels indicating rFGF1 is not an insulin-mimetic (Fig. 3a). However, pre-treatment of STZ mice with rFGF1 markedly enhanced the glucose lowering effects of exogenously supplied insulin (Fig. 3b, c). Conversely, the rFGF1-dependent increase in metabolic clearance rate was severely blunted when insulin secretion was inhibited by somatostatin (Fig. 3d-g). Improved insulin sensitivity often correlates with reduced systemic inflammation and indeed chronic treatment of ob/ob mice with rFGF1 reduced serum levels of several inflammatory cytokines (Eotaxin, KC, Mip-1b, IL-3) (Extended Data Fig. 3d). These results demonstrate 
that rFGF1 operates in an insulin-dependent manner to lower blood glucose and suggest parenteral rFGF1may act as an insulin sensitizer.

To further investigate the physiological mechanisms of rFGF1 action, we performed hyperinsulinemic-euglycemic clamp studies in DIO mice chronically treated with vehicle or rFGF1. The steady state glucose infusion rate (GIR) during the clamp was $\sim 75 \%$ higher in rFGF1-injected mice indicating increased insulin responsiveness (Extended Data Fig. 4a). The ability of insulin to suppress hepatic glucose production (HGP) was improved in rFGF1-injected mice revealing increased hepatic insulin sensitivity as a long-term consequence of rFGF1 injection (Fig. 4a). Interestingly, liver gene expression analyses from chronic $\mathrm{rFGF1-treated} \mathrm{DIO} \mathrm{mice} \mathrm{revealed} \mathrm{significant} \mathrm{reductions} \mathrm{in} \mathrm{macrophage} \mathrm{markers,}$ e.g. F4/80, Cdll c , and inflammatory cytokines, e.g. Il-1 $a, I l-1 \beta$, Tnf- $a$ (Extended Data Fig. $4 b)$. Furthermore, whole body and insulin stimulated glucose disposal rates (GDR and ISGDR) were $\sim 47 \%$ and $\sim 80 \%$ higher, respectively, in rFGF1-injected mice, reflecting enhanced peripheral insulin sensitivity (Fig. 4b, c, Extended Data Fig. 4c-f). Consistent with the hepatic and peripheral insulin sensitizing effects of $\mathrm{rFGF}$, insulin stimulated AKT signaling was enhanced in both the liver and muscle of chronic rFGF1-treated DIO mice (Extended Data Fig. 4g, h). Taken together, these findings demonstrate that chronic administration of rFGF1 leads to sustained glucose lowering and whole body insulin sensitization.

The above studies demonstrating robust and sustained glucose lowering in multiple diabetic mouse models raised the possibility of parenteral rFGF1 as a diabetic therapy. In support of this notion, diabetic mice chronically treated with $\mathrm{rFGF} 1$ were phenotypically normal in terms of locomotor activity, oxygen consumption, and respiratory exchange ratio (RER) (Extended Data Fig. 4i-n) suggesting chronic rFGF1 treatment does not evoke adverse pleiotropic effects. While endogenous FGF1 has been demonstrated to play a role in adipose remodeling, histological examination of this tissue found no abnormalities after chronic rFGF1 treatment (Extended Data Fig. 4o). Furthermore, serum creatine kinase levels did not change in chronic rFGF1-treated ob/ob mice indicating the absence of muscle tissue damage (Extended Data Fig. 4p).

While thiazolidinediones (TZDs) are the only therapeutic insulin sensitizers, their application is limited by adverse side effects including weight gain, increased liver steatosis and bone fractures ${ }^{5}$. Notably, chronic rFGF1 treatment did not lead to weight gain, and reduced hepatic steatosis (Fig. 2f, Extended Data Fig. 2i, j, Extended Data Table 1). Similar to TZDs, endocrine FGF21, which has recently been shown to have potential therapeutic blood glucose lowering effects, has also been associated with loss of bone density ${ }^{14}$. In contrast, bone mineral density, trabecular bone architecture and cortical bone thickness was not affected by chronic rFGF1 treatment in DIO mice, as determined by micro CT analyses (Extended Data Fig. 4q, r). Furthermore, total and high molecular weight (HMW) serum adiponectin levels were not altered by chronic $\mathrm{rFGF} 1$ treatment, differentiating its mechanism of action from the adiponectin-dependent glucose lowering effects of FGF21 ${ }^{15,16}$ (Extended Data Fig. 4s). As the prototype of a growth factor family, rFGF1 has the potential to induce unwanted cell proliferation and concern resides in whether the mitogen properties of $\mathrm{rFGF} 1$ could be dissociated from its glucose lowering activities. To 
address this question we generated an FGF1 ligand that lacks the first 24 residues from the $\mathrm{N}$-terminus, $\mathrm{rFGF}^{\Delta \mathrm{NT}}$. Based on the crystal structures of FGF1-FGFR complexes, the truncation was predicted to have significant effects on the binding affinity of FGF1 for all FGFRs, and similar truncations have been shown to reduce FGF1 mitogenicity. Consistent with this prediction, $\mathrm{rFGF}{ }^{\Delta \mathrm{NT}}$ showed a dramatic reduction in binding affinity for FGFRs compared to the native ligand, yet still was able to bind FGFR1c and FGFR2c, albeit with lower affinity. In vitro, $\mathrm{rFGF}^{\triangle \mathrm{NT}}$ showed a somewhat attenuated ability to activate intracellular signals downstream of FGFRs but displayed a severe reduction in mitogenic activity (Fig 4d and Extended Data Fig. 5a, 5b, 6a). Remarkably, parenteral delivery of $\mathrm{rFGF}{ }^{\Delta \mathrm{NT}}$ dose-dependently lowered blood glucose levels in both genetic- and diet-induced mouse models of diabetes (Fig 4e, $\mathrm{f}$ and Extended Data Fig. 6b). rFGF1 ${ }^{\Delta \mathrm{NT}}$ also retained the feeding suppression effects observed with rFGF1 (Extended Data Fig. 6c). Therefore, the synthetic effects of exogenous rFGF1 on physiology, such as glucose homeostasis and feeding behavior, differ from and are independent of its classical role as a growth factor and mitogen.

In exploring the receptor dependency of the observed glucose lowering effects, we hypothesized that the effects are mediated through FGFR1, based on its known role in insulin sensitivity ${ }^{10}$ and the observation that $\mathrm{rFGF}^{\mathrm{ANT}}$ retained FGFR1c binding affinity in our SPR studies. Furthermore, our previous studies on Fgfl knockout mice implicated adipose tissue as a major site of FGF1 action. Accordingly, we generated mice lacking Fgfrl predominantly in adipose tissue (aP2-Cre; $F g f r l \mathrm{fl} / \mathrm{fl}, \mathrm{R} 1 \mathrm{KO}$ mice). Indeed, while $\mathrm{rFGF} 1$ potently lowered blood glucose levels in control diabetic mice, $r F G F 1$ failed to lower glucose in the R1 KO mice (Fig 4g), indicating a requirement for FGFR1. Consistent with this, $\mathrm{rFGF} 1^{\Delta \mathrm{NT}}$ similarly failed to affect blood glucose in R1 KO mice (Extended Data Fig. 6d). Importantly, an FGF1 analog with severely attenuated FGFR-mediated signaling in vitro (FGF1 L29 to D155; rFGF1 ${ }^{\Delta \mathrm{NT} 2}$ ) did not significantly affect blood glucose levels in diabetic mice (Extended Data Fig. 6e, f), further supporting the notion that FGFR1-mediated signaling is required for the glucose lowering effects of parenteral rFGF1. Taken together, these studies identify exogenous or endocrine $\mathrm{rFGF} 1$ as a potent and long-lasting insulin sensitizer that appears to circumvent the adverse side effects associated with other diabetic therapies.

Previously, we identified a role for endogenous FGF1 in the adaptive remodeling of visceral adipose tissue in response to nutrient fluctuations. The profound metabolic dysregulation observed in FGF1 knockout mice when stressed by a high fat diet was associated with reduced vascularity in visceral adipose depots, consistent with the known role of FGF1 in angiogenesis. In contrast, our current findings identify a neomorphic insulin sensitizing action for FGF1 in which systemic delivery of the normally autocrine/paracrine FGF1 through parenteral routes results in potent and sustained correction of hyperglycemia accompanied by whole body insulin sensitization.

The apparent divergent in vivo activities now ascribed to FGF1 appear to closely parallel those of FGF21, which has been assigned locally-restricted roles in adipose tissue, as well as systemic glucose lowering activities. However, FGF21 circulates as a true endocrine hormone, whereas the high affinity HSPG binding activity and serum lability of FGF1 
restricts its endogenous actions to local tissues and results in the rapid clearance of exogenous FGF1 from the circulation ${ }^{1}$. In addition, these two FGFs have disparate FGFR specificities; while FGF1 can bind and signal through each of the alternatively spliced forms of the FGFRs, FGF2 1 signaling requires a heterodimeric $\beta$-klotho/FGFR complex ${ }^{7}$. Our findings indicate that the metabolic effects of exogenous FGF1 are mediated through FGFR1 in adipose tissue, however additional studies will be necessary to exclude the involvement of additional receptors and/or tissues in the bodywide effects attributed to parenterally delivered rFGF1. In conclusion, given that the glucose-lowering effects of rFGF1 were not accompanied by side-effects associated with current insulin sensitizers, along with the discovery that non-mitogenic $\mathrm{rFGF}^{\Delta \mathrm{NT}}$ retains glucose normalizing capability, rFGF1 and its derivatives may hold therapeutic promise.

\section{Online Methods}

Animals

Mice were housed in a temperature-controlled environment with a 12-hr light/12-hr dark cycle and handled according to Salk IACUC guidelines complying with U.S. legislation. Male ob/ob mice (B6.V-Lep ${ }^{\text {ob } / J, ~ J a c k s o n ~ l a b o r a t o r i e s) ~ a n d ~ m a l e ~ C 57 B L / 6 J ~ m i c e ~ r e c e i v e d ~ a ~}$ standard or high fat diet (MI laboratory rodent diet 5001, Harlan Teklad; high fat (60\%) diet F3282, Bio-Serv) and acidified water ad libitum. STZ-induced diabetic mice in the C57BL/6J background were purchased from Jackson laboratories. aP2-Cre mice (B6.Cg$\mathrm{Tg}$ (Fabp4-cre)1Rev/J, Jackson laboratories) were crossed to FGFR1 floxed mice (B6.129S4Fgfr1tm5.1Sor/J, Jackson laboratories) to generate aP2-Cre; FGFR1 fl/fl mice. $0.1 \mathrm{mg} / \mathrm{ml}$ solutions in PBS of mouse FGF1 (Prospec, Ness Ziona, Israel), human FGF1 (Prospec, Ness Ziona, Israel), mouse FGF2 (Prospec, Ness Ziona, Israel), mouse FGF9 (Prospec, Ness Ziona, Israel), and mouse FGF10 (R\&D systems) were injected as described. Heparin sodium salt (Sigma) was premixed with $\mathrm{mFGF1}$ peptide prior to injection.

\section{Serum analysis}

Blood was collected by tail bleeding either in the ad libitum fed state or following overnight fasting. Free fatty acids (Wako), triglycerides (Thermo) and cholesterol (Thermo) were measured using enzymatic colorimetric methods following the manufacturer's instructions. Serum insulin levels were measured using an insulin ELISA kit (Millipore). Plasma adipokine and cytokine levels were measured using Milliplex ${ }^{\mathrm{TM}}$ MAP and Bio-Plex Pro $^{\mathrm{TM}}$ kits (Millipore and Bio-Rad).

\section{Histological analysis}

Tissues were fixed in $4 \%$ phosphate-buffered formalin, embedded in paraffin, and sectioned at $4 \mu \mathrm{m}$. Sections were stained with hematoxylin and eosin or periodic acid-Schiff reagent according to standard procedures.

\section{Metabolite analysis}

Hepatic concentrations of triglycerides, free cholesterol and total cholesterol were measured in homogenized livers using commercial kits (Roche Diagnostics, Wako Chemicals, Neuss, Germany and DiaSys, Holzheim, Germany) after lipid extraction according to Bligh and 
Dyer and lipids were redissolved in 2\% Triton X-100 in water. Glycogen in liver was determined after extraction of $100 \mathrm{mg}$ liver with $\mathrm{KOH}$.

\section{Metabolic studies}

Glucose tolerance tests (GTT) were conducted after o/n fasting. Mice were injected i.p. with $1 \mathrm{~g}$ of glucose per/kg bodyweight and blood glucose was monitored at $0,15,30,60$, and 120 min using a OneTouch Ultra glucometer (Lifescan Inc). Insulin tolerance tests (ITT) were conducted after $3 \mathrm{hr}$ fasting. Mice were injected i.p. with $2 \mathrm{U}$ of insulin $/ \mathrm{kg}$ bodyweight (Humulin R; Eli Lilly) and blood glucose was monitored at 0, 15, 30, 60, and 90 min using a OneTouch Ultra glucometer (Lifescan Inc). Real-time metabolic analyses were conducted in a Comprehensive Lab Animal Monitoring System (Columbus Instruments). $\mathrm{CO}_{2}$ production, $\mathrm{O}_{2}$ consumption, $\mathrm{RQ}$ (relative rates of carbohydrate versus fat oxidation), and ambulatory counts were determined for six consecutive days and nights, with at least $24 \mathrm{~h}$ for adaptation before data recording. Total body composition analysis was performed using an EchoMRI-100 ${ }^{\mathrm{TM}}$ (Echo Medical Systems, LLC).

\section{STZ mice}

STZ mice (Jackson Laboratory) injected sc with control PBS or $0.5 \mathrm{mg} / \mathrm{kg}$ rFGF1 were subsequently fasted for $8 \mathrm{hrs}$ prior to blood glucose measurements (OneTouch Ultra glucometer, Lifescan Inc). STZ mice injected sc with control PBS or $0.5 \mathrm{mg} / \mathrm{kg} \mathrm{rFGF} 1$ were subsequently fasted for $8 \mathrm{hrs}$ prior to injection of $0.25 \mathrm{U} / \mathrm{kg}$ insulin (Humulin R; Eli Lilly) and blood glucose was monitored at 0,30, 60, and $120 \mathrm{~min}$ (OneTouch Ultra glucometer, Lifescan Inc).

\section{Hyperinsulinemic-euglycemic clamp in DIO mice}

Mouse clamps were performed as previously described ${ }^{17}$. Male C57BL/6J mice received a high fat diet (MI laboratory rodent diet 5001, Harlan Teklad; high fat (60\%) diet F3282, Bio-Serv) for 16 weeks and treated with vehicle (PBS) or $\mathrm{rFGF} 1(0.5 \mathrm{mg} / \mathrm{kg})$ by sc injection every $48 \mathrm{~h}$ for 3 weeks prior to clamp studies. Briefly, mice implanted with dual jugular catheters 3 days prior were fasted for $6 \mathrm{hr}$ fast, then equilibrated with tracer $(5.0 \mu \mathrm{Ci} / \mathrm{h}, 0.12$ $\mathrm{ml} / \mathrm{h}$ [3- $\left.{ }^{3} \mathrm{H}\right] \mathrm{D}$-glucose, NEN Life Science Products) for $90 \mathrm{~min}$. A basal blood sample was then drawn via tail vein to calculate basal glucose uptake. The insulin $(8 \mathrm{mU} / \mathrm{kg} / \mathrm{min}$ at $2 \mu \mathrm{l} /$ min, Novo Nordisk) plus tracer $(5.0 \mu \mathrm{Ci} / \mathrm{h})$ and glucose $(50 \%$ dextrose at variable rate, Abbott) infusions were initiated simultaneously, with the glucose flow rate adjusted to reach a steady state blood glucose concentration ( 120 min). Steady state was confirmed by stable plasma tracer counts during the final $30 \mathrm{~min}$ of clamp. Blood was taken at 110 and 120 minutes for the determination of tracer-specific activity. At steady state, the rate of glucose disappearance or the total GDR is equal to the sum of the rate of endogenous or HGP plus the exogenous GIR. The IS-GDR is equal to the total GDR minus the basal glucose turnover rate.

\section{Glucose flux measurements}

Mice were equipped with a permanent catheter in the right atrium via the jugular vein ${ }^{18}$ and were allowed a recovery period of at least 3 days. After the recovery period, the mice were 
placed in experimental cages with access to drinking water. All infusion experiments were performed in conscious, unrestrained mice. Steady state glucose fluxes were determined during three periods: 1) basal hyperglycemic, 2) after FGF1 administration and 3) after somatostatin infusion. During the entire experiment, mice were infused with a solution containing a tracer of $\left[\mathrm{U}^{13} \mathrm{C}\right]$ glucose $(10 \mathrm{mg} / \mathrm{ml})$ (Cambridge Isotope Laboratories, Andover, MA) at an infusion rate of $0.6 \mathrm{ml} / \mathrm{h}$. After the basal period ( $\sim 3 \mathrm{hrs})$, mice were administered a bolus of recombinant FGF1 $(0.5 \mathrm{mg} / \mathrm{kg})$ and steady state glucose fluxes were determined after blood glucose levels were stable (about $2 \mathrm{hrs).} \mathrm{Finally,} \mathrm{somatostatin}$ $(10 \mu \mathrm{g} / \mathrm{ml})$ was added to the infusate and effects on glucose fluxes were monitored. During the experiment, blood glucose levels were determined every 15 min using a Lifescan EuroFlash glucose meter. For GC-MS analysis of $\left[\mathrm{U}^{13} \mathrm{C}\right]$ glucose, bloodspots on filter paper were collected from the tail vein every $30 \mathrm{~min}$.

\section{Purification of FGF and FGFR proteins}

Human FGF1 (M1 to D155), N-terminally truncated human FGF1s (FGF1 ${ }^{\Delta \mathrm{NT}}$; K25 to D155 and FGF1 ${ }^{\Delta \mathrm{NT} 2}$; L29 to D155), and human FGF homologous factor 1B (FHF1B; M1 to T181) were expressed in Escherichia coli cells and purified from the soluble bacterial cell lysate fraction by heparin affinity, ion exchange, and size exclusion chromatographies. The minimal ligand-binding domain of human FGFR1c (D142 to R365), FGFR2b (A140 to E369), FGFR2c (N149 to E368), FGFR3c (D147 to E365), and FGFR4 (Q144 to D355) was refolded in vitro from bacterial inclusion bodies and purified by published protocols.

\section{FGF1-FGFR binding analysis by Surface Plasmon Resonance Spectroscopy}

Real time binding experiments were performed with a Biacore 2000 Surface Plasmon Resonance (SPR) spectrometer (Biacore AB/GE Healthcare). FGF1-FGFR binding was studied at $25^{\circ} \mathrm{C}$ in HBS-EP buffer (10 mM HEPES-NaOH, pH 7.4, $150 \mathrm{mM} \mathrm{NaCl}, 3 \mathrm{mM}$ EDTA, $0.005 \%$ (v/v) polysorbate 20$)$. FGF1 and FGF1 ${ }^{\Delta \mathrm{NT}}$ were covalently coupled to sample flow channels of a research grade CM5 chip ( 60 to $\left.99 \mathrm{fmol} \mathrm{mm}^{-2}\right)$. FHF1B, which shares structural similarity with FGFs but does not exhibit any FGFR binding, was coupled to the control flow channel of the chip $\left(\sim 63 \mathrm{fmol} \mathrm{mm}^{-2}\right)$. Increasing concentrations of the ligand-binding domain of FGFRs ( 5 to $960 \mathrm{nM}$ ) were injected over the chip at a flow rate of $50 \mu \mathrm{min}^{-1}$, and at the end of each protein injection (180 s), HBS-EP buffer $\left(50 \mu \mathrm{min}^{-1}\right)$ was flowed over the chip to monitor dissociation for $180 \mathrm{~s}$. The chip surface was then regenerated by injecting 10 to $50 \mu \mathrm{l}$ of $1.5 \mathrm{M} \mathrm{NaCl}$ in $10 \mathrm{mM}$ HEPES-NaOH, $\mathrm{pH}$ 7.5. The data were processed with BiaEvaluation software (Biacore AB/GE Healthcare). For each FGFR injection over the chip, the nonspecific responses from the FHF1B control flow channel were subtracted from the responses recorded for the FGF1 flow channel. Where possible, equilibrium dissociation constants $\left(\mathrm{K}_{\mathrm{D}} \mathrm{s}\right)$ were calculated from fitted saturation binding curves. The fitted curves were judged to be accurate based on the distribution of the residuals (even and near 0$)$ and $\chi^{2}\left(<10 \%\right.$ of $\left.\mathrm{R}_{\max }\right)$.

\section{Mitogenicity assay}

NIH3T3 cells from ATCC (not recently tested for mycoplasma contamination) were seeded in 96 -well plates at a density of $5 \times 10^{3}$ cells per well. $24 \mathrm{hr}$ later, the cells were washed with 
PBS and then serum-starved for $24 \mathrm{hr}$. Starved cells were stimulated with rFGF1 or $\mathrm{rFGF}^{\Delta \mathrm{NT}}\left(0.097\right.$ to $\left.25 \mathrm{ng} \mathrm{ml}^{-1}\right)$ for $24 \mathrm{hr}$, and the number of viable cells was measured using the MTT assay.

\section{Intracellular signaling assay}

To analyze Akt signaling, mouse tissues were homogenized in Bio-Plex cell lysis kit solution (Bio-Rad) and lysates were analyzed for total and phospho-Akt following manufacturer's instructions for the Bio-Plex phosphoprotein detection system (Bio-Rad). For in vitro FGF signaling assays, HEK293 cells were seeded in 6-well plates and grown to $70-80 \%$ confluence. Following overnight serum starvation in DMEM cells were treated with recombinant peptides for $15 \mathrm{~min}$, washed in ice-cold PBS, and frozen in liquid nitrogen. Cells were lysed in sample buffer, sonicated, resolved on SDS-PAGE, and blotted to PVDF membranes for antibody detection. pFRS2a, ERK1/2, phospho-ERK1/2, Akt and phospho-Akt antibodies were purchased from Cell Signaling Technology.

\section{Statistics and general methods}

Age and weight matched mice (average cohort size 6 to 10 sufficient to enable statistical significance to be accurately determined) were randomly assigned to treatment or control groups. No animals were excluded from the statistical analysis, and the investigators were not blinded in the studies. Appropriate statistical analyses (t-test) were applied, assuming a normal sample distribution, as specified in the figure legends. No estimate of variance was made between each group. 


\section{Extended Data}

a

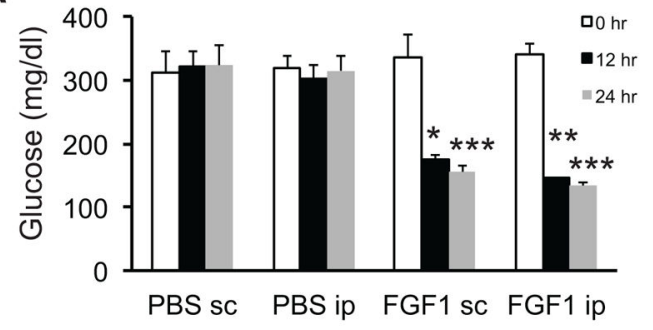

C

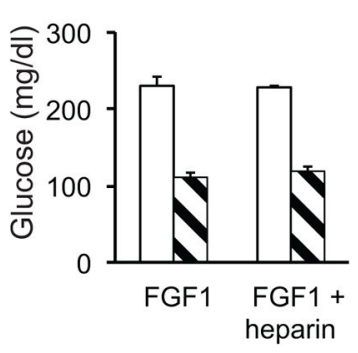

f

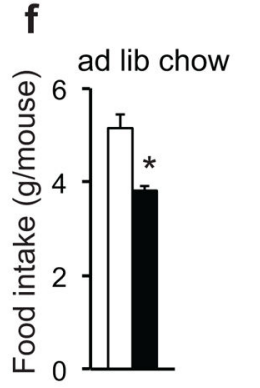

d

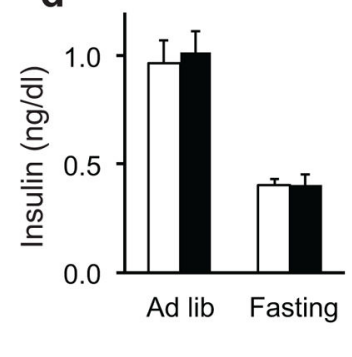

h

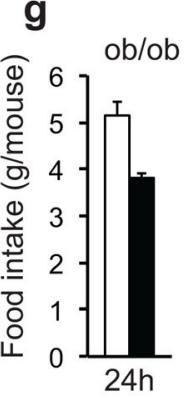

b
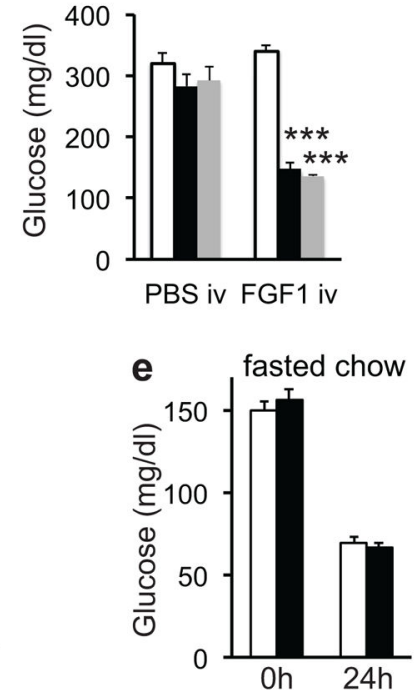

Extended Data Fig. 1. Acute rFGF1 injection lowers blood glucose levels and reduces food intake Blood glucose levels in ob/ob mice after (a) subcutaneous (sc, $n=3$ ), intraperitoneal (ip, $n=3)$, (b) intravenous (iv) injection of $\mathrm{rFGF} 1(\mathrm{n}=6)$ or control vehicle $(\mathrm{n}=5)$, or (c) sc injection of rFGF1 premixed with heparin $(1.5 \mathrm{mg} / \mathrm{kg}, \mathrm{n}=3)$. (d) Serum insulin levels $24 \mathrm{hrs}$ after rFGF1 treatment under ad lib fed or fasting conditions in chow fed C57BL/6J mice $(\mathrm{n}=10)$. (e) Blood glucose levels in fasted, chow fed mice after rFGF1 treatment $(\mathrm{n}=8)$. $(\mathbf{f})$ Food intake during 24 hrs post-injection of rFGF1 in chow fed C57BL/6J mice ( $\mathrm{n}=8)$. Food intake during indicated times post-injection of rFGF1 in $(\mathbf{g})$ ob/ob $(n=6),(\mathbf{h}) \mathrm{db} / \mathrm{db}(\mathrm{n}=3)$, and (i) DIO (n=6) mice. Control PBS (open bar) or murine rFGF1 (0.5 mg/kg, filled bar) were injected sc to ad lib fed mice unless otherwise noted. Values are means \pm SEM. Statistics by two-tailed $t$ test. $* P<0.05, * * P<0.01$ 

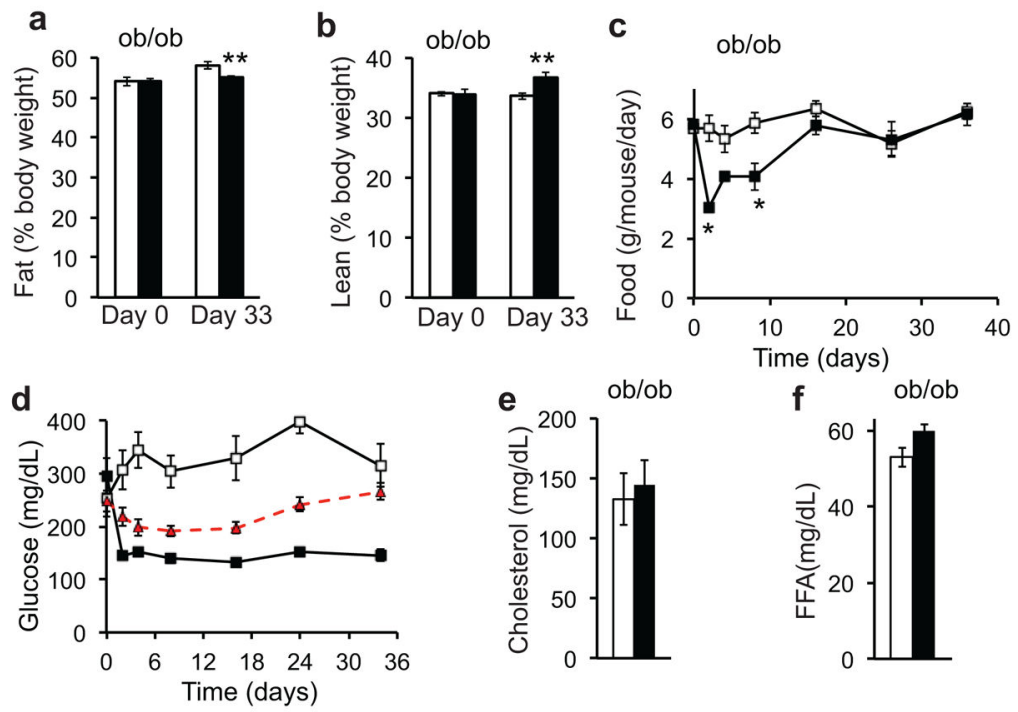

9
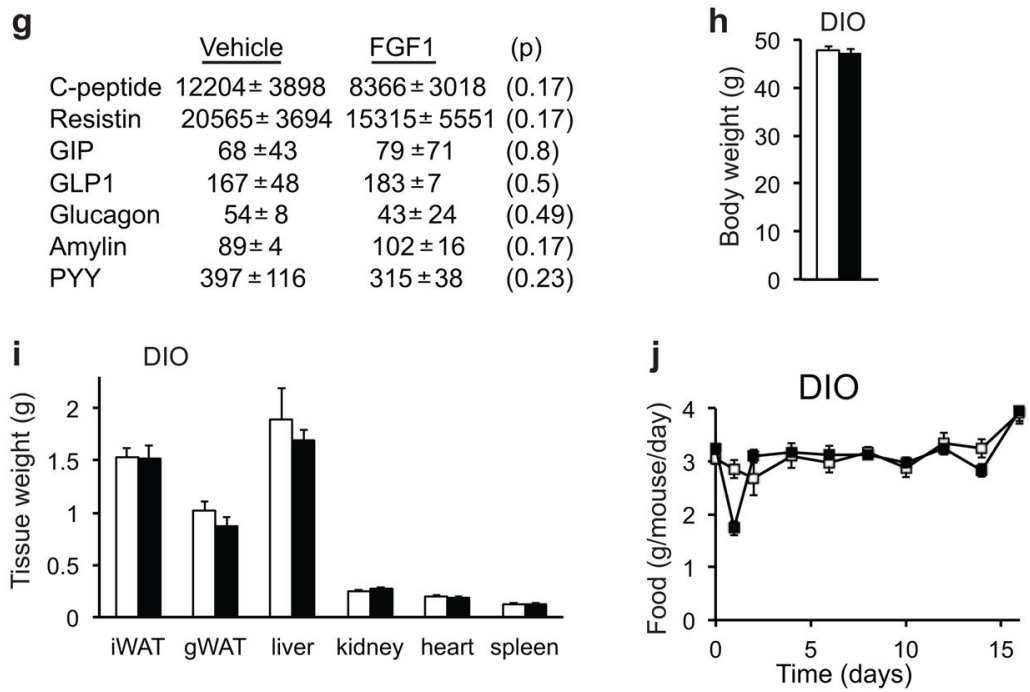

Extended Data Fig. 2. Chronic administration of rFGF1 lowers blood glucose independent of food intake and metabolic hormones

MRI analyses of (a) fat and (b) lean mass content at indicated days, and (c) food intake during chronic administration of control vehicle $(n=6)$ or rFGF1 $(n=8)$ in ob/ob mice. (d) Random fed blood glucose of a pair-fed cohort of ob/ob mice (red line, filled triangles) plotted alongside blood glucose trends during chronic administration of control vehicle (black line, open squares) or rFGF1 in ob/ob mice (black line, filled squares, $n=6$ ). Pair-fed cohort food intake was restricted to equal the food intake of rFGF1 injected ob/ob mice throughout the 5 week trial. (e) Serum cholesterol, (f) free fatty acids, and (g) metabolic hormone levels after 5 week administration of control PBS or rFGF1 in ob/ob mice $(n=4)$. (h) Body weight, (i) tissue mass analyses, and (j) food intake of DIO mice after 4 weeks of rFGF1 treatment $(n=6)$. All injections were performed sc with control vehicle (PBS, open bars or symbols) or murine rFGF1 $(0.5 \mathrm{mg} / \mathrm{kg}$, closed bars or symbols $)$ to ad lib fed mice every 48 hrs throughout chronic administration trials. Values are means \pm SEM. Statistics by two-tailed $t$ test. ${ }^{*} P<0.05$, $* * P<0.01$ 
a

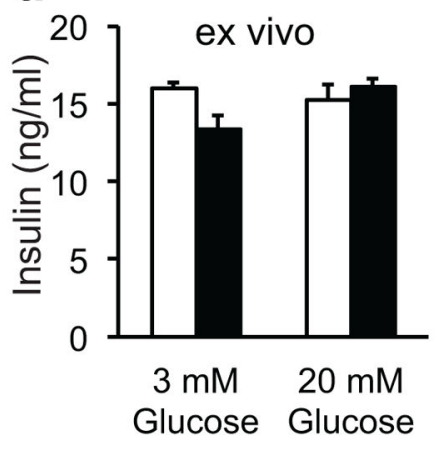

b

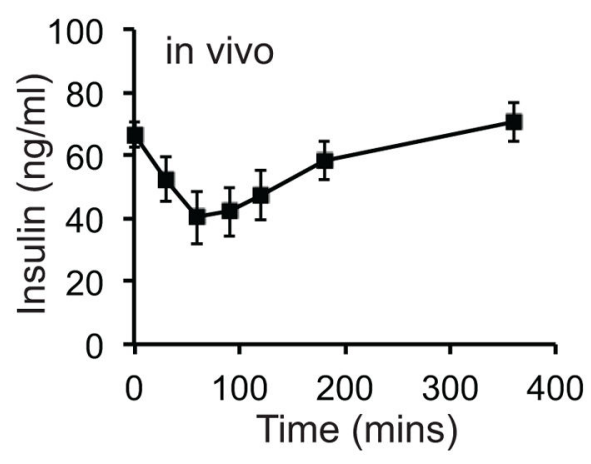

d

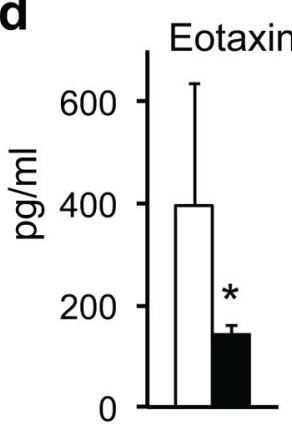

C
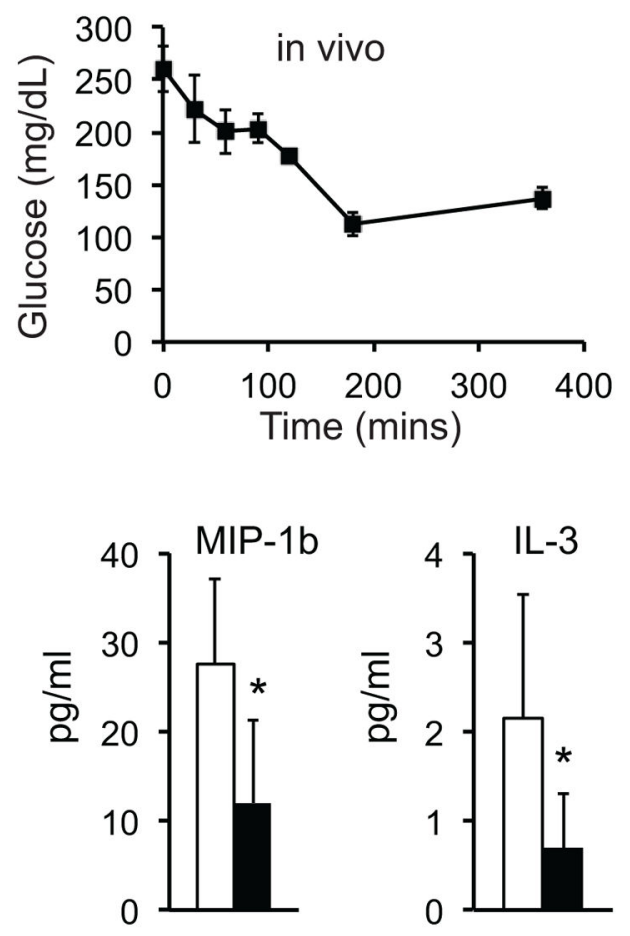

Extended Data Fig. 3. rFGF1 does not stimulate insulin secretion and chronic administration reduces systemic inflammation

(a) Glucose-stimulated insulin secretion (3 $\mathrm{mM}$ glucose, basal; $20 \mathrm{mM}$ glucose, stimulated) of ob/ob islets after $1 \mathrm{hr}$ pre-treatment with control PBS (open bars) or rFGF1 (10 ng/ml, filled bars, $n=6$ ). Time course of (b) serum insulin and (c) blood glucose levels in ob/ob mice after a single rFGF1 injection $(0.2 \mathrm{mg} / \mathrm{kg}$ iv, $\mathrm{n}=8)$. (d) Serum cytokines in ob/ob mice after 5 week sc administration of control vehicle (PBS, open bars, n=4) or rFGF1 (0.5 mg/kg q.a.d., filled bars, $\mathrm{n}=6$ ) Values are means \pm SEM. Statistics by two-tailed $t$ test. $* P<0.05$, $* * P<0.01$ 


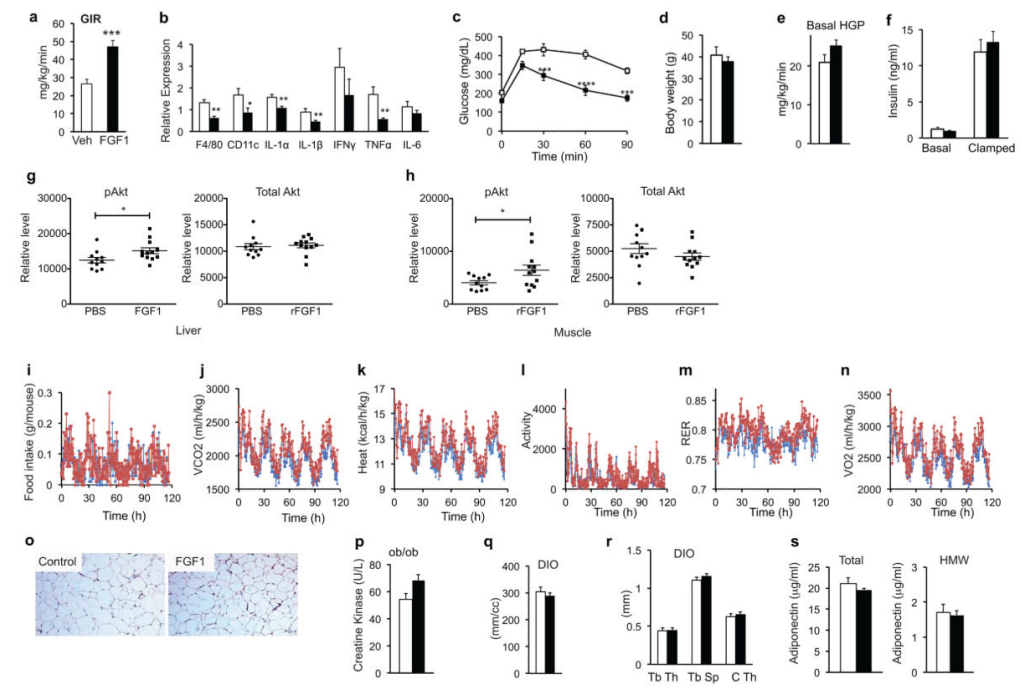

Extended Data Fig. 4. rFGF1 is an insulin sensitizer and does not affect bone morphology (a) Steady state glucose infusion rate (GIR), (b) hepatic inflammation-related gene expression, (c) glucose tolerance tests, and (d) body weights of DIO mice after 3 weeks administration of control PBS $(n=11)$ or rFGF1 (0.5 mg/kg, q.a.d., $n=9)$. (e) Basal hepatic glucose production and (f) basal and clamped serum insulin concentrations measured during hyperinsulinemic-euglycemic clamp studies of DIO mice after 3 weeks administration of control PBS ( $n=11)$ or rFGF1 (n=9). (g) Insulin induced phosphorylation of Akt in liver and (h) muscle tissues of DIO mice after 3 weeks administration of control PBS $(n=11)$ or rFGF1 (n=12) (i) Food intake, (j) carbon dioxide production, (k) heat production, (l) total activity, $(\mathbf{m})$ respiratory exchange ratio (RER), and (n) oxygen consumption of chronic rFGF1-treated DIO mice (3 weeks treatment of control PBS (blue symbols) or rFGF1 (red symbols, $n=4$ ), measured in metabolic cages. (o) Representative hematoxylin and eosin staining of inguinal white adipose tissue from DIO mice after 4 weeks administration of control PBS or rFGF1 (n=6). (p) Serum creatine kinase levels in chronic rFGF1-treated ob/ob mice ( $\mathrm{n}=4)$. (q) Bone mineral density and (r) trabecular bone thickness ( $\mathrm{Tb} \mathrm{Th})$ and space (Tb Sp), and cortical bone thickness (C Th) in 4 week treated DIO mice analyzed by $\mu$ Computed Tomography $(\mathrm{n}=6)$. (s) Total and high molecular weight (HMW) serum adiponectin levels in ob/ob mice after 4 weeks of rFGF1 injections every $48 \mathrm{hrs}(\mathrm{n}=4)$. Control vehicle (PBS, open bar), $\mathrm{rFGF} 1(0.5 \mathrm{mg} / \mathrm{kg}$ sc, filled bars). Values are means \pm SEM. Statistics by two-tailed $t$ test. $* P<0.05$, $* * P<0.01, * * * P<0.005$, **** $P<0.001$ 
a
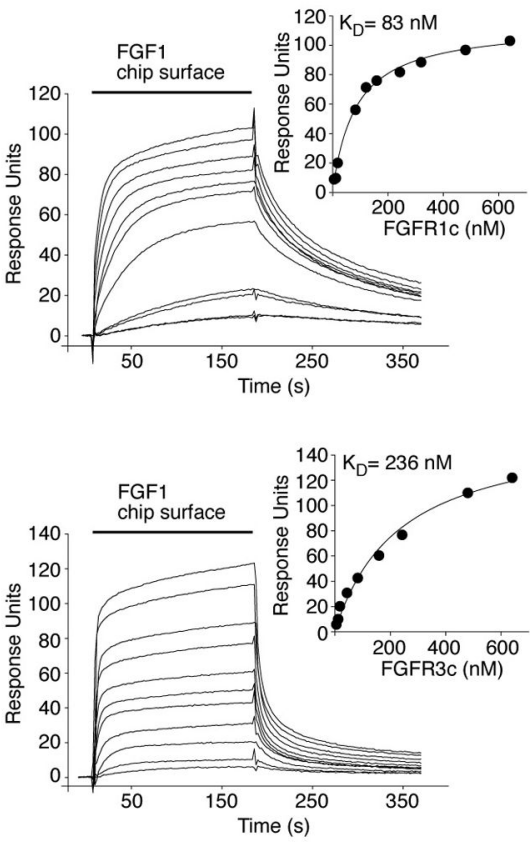

b
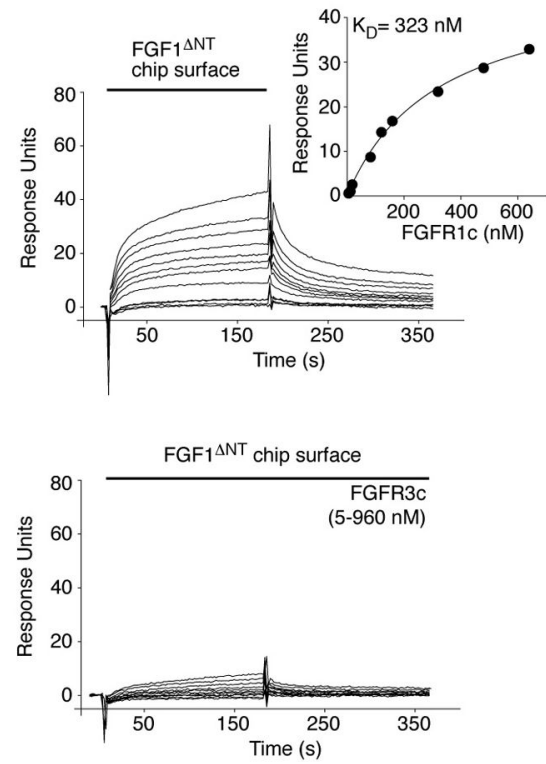
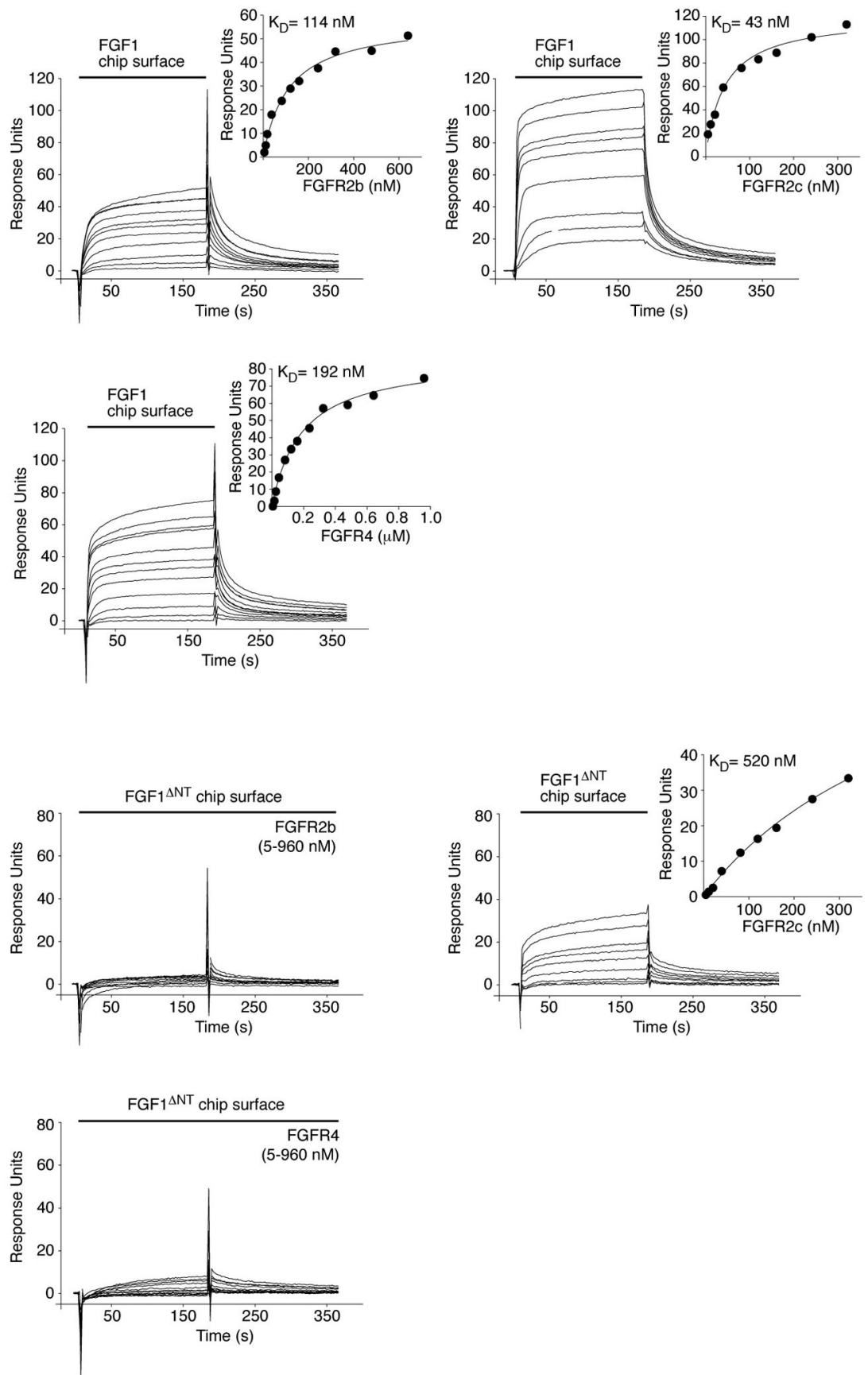

Extended Data Fig. 5. Binding affinities of rFGF1 and rFGF1 ${ }^{\triangle N T}$ to FGFRs

Removal of the N-terminus from FGF1 reduces the ligand's binding affinity for FGFRs. (a) Overlays of SPR sensorgrams of FGF1 binding to the ligand-binding domain of FGFRs and fitted saturation binding curves. Equilibrium dissociation constants $\left(\mathrm{K}_{\mathrm{D}} \mathrm{s}\right)$ were derived from the saturation binding curves. (b) Overlays of SPR sensorgrams of FGF1 ${ }^{\Delta \mathrm{NT}}$ binding to the ligand-binding domain of FGFRs. Where possible, $\left(\mathrm{K}_{\mathrm{D}} \mathrm{s}\right)$ were calculated from fitted saturation binding curves. 

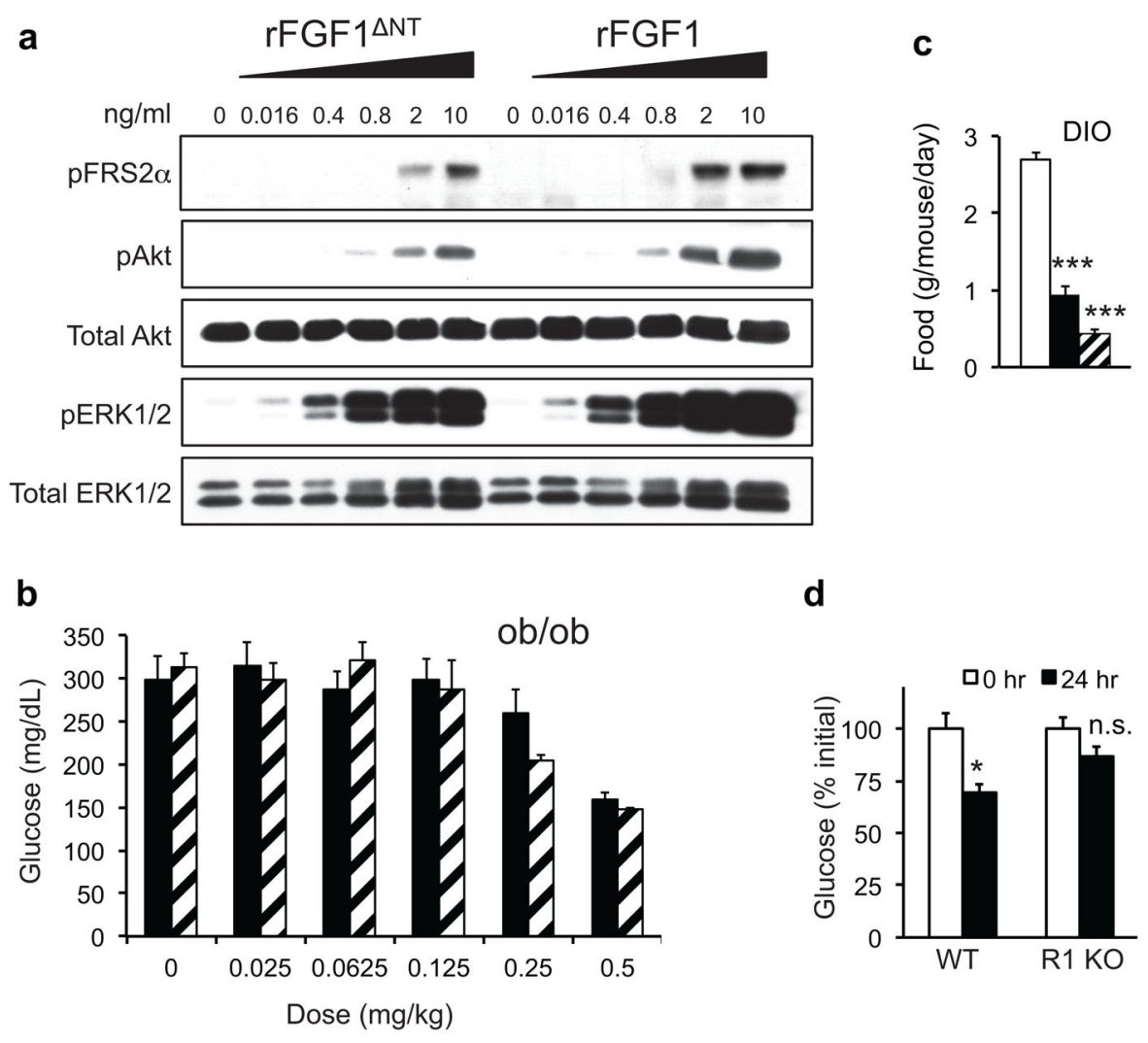

d

e manner
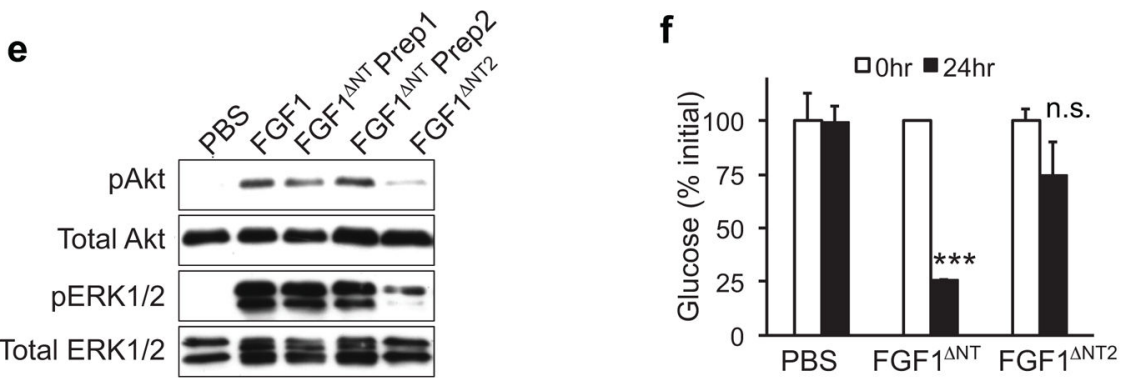

Extended Data Fig. 6. rFGF1 and rFGF1 ${ }^{\triangle N T}$ signal through FGFR1 in a dose-dependent

(a) Western blot showing intracellular signaling in serum starved HEK293 cells after a 15 min treatment with the indicated concentrations of PBS, rFGF1 ${ }^{\triangle \mathrm{NT}}$, or rFGF1. (b) Dose response of glucose lowering effects of sc delivered $\mathrm{rFGF}^{\mathrm{\Delta NT}}$ (striped bars) in comparison to rFGF1 (filled bars) in 12 week old ob/ob mice $(n=8)$. (c) Food intake in DIO mice during $24 \mathrm{hr}$ period after injection of control PBS (open bar), $\mathrm{rFGF} 1(0.5 \mathrm{mg} / \mathrm{kg} \mathrm{sc}$, filled bars), or $\mathrm{rFGF}{ }^{\mathrm{NTT}}(0.5 \mathrm{mg} / \mathrm{kg} \mathrm{sc}$, striped bar, $\mathrm{n}=10)$. (d) Blood glucose levels in high-fat diet fed (8 mos) $F g f r l \mathrm{fl} / \mathrm{fl}(\mathrm{WT}, \mathrm{n}=5)$ and aP2-Cre; $F g f r l \mathrm{fl} / \mathrm{fl}(\mathrm{R} 1 \mathrm{KO}, \mathrm{n}=4)$ mice at 0 (open bars) and $24 \mathrm{hrs}$ (filled bars) after $\mathrm{rFGF} 1^{\triangle \mathrm{NT}}$ treatment $(0.5 \mathrm{mg} / \mathrm{kg} \mathrm{sc})$. (e) Western blot showing intracellular signaling in serum starved HEK293 cells after a 15 min treatment with of PBS or $10 \mathrm{ng} / \mathrm{ml}$ of $\mathrm{rFGF} 1$, two independent preparations of $\mathrm{rFGF} 1^{\triangle \mathrm{NT}}$, and $\mathrm{rFGF} 1^{\triangle \mathrm{NT}} 2$. (f) Blood glucose levels in ob/ob mice at 0 (open bars) and $24 \mathrm{hrs}$ (filled bars) after $\mathrm{rFGF} 1^{\Delta \mathrm{NT}}$ and $\mathrm{rFGF} 1^{\Delta \mathrm{NT} 2}$ treatment $(0.5 \mathrm{mg} / \mathrm{kg} \mathrm{sc})(\mathrm{n}=2)$. Gel images are representative of at least 3 
biological replicates. Values are means \pm SEM. Statistics by two-tailed $t$ test. $* P<0.05$, $* * * P$ $<0.005$

\section{Extended Data Table 1 \\ Metabolic parameters of ob/ob mice chronically treated with rFGF1}

Male ob/ob mice injected subcutaneously with vehicle (PBS) or rFGF1 $(0.5 \mathrm{mg} / \mathrm{kg} / 3$ days) for 36 days.

\begin{tabular}{lccl}
\hline & vehicle & FGF1 & \\
Body weight (BW) & $70.0 \pm 1.8$ & $65.1 \pm 1.9$ & gram \\
Liver & $4.26 \pm 0.15$ & $3.77 \pm 0.22$ & gram \\
iWAT & $3.71 \pm 0.09$ & $3.22 \pm 0.12$ & gram \\
gWAT & $1.46 \pm 0.05$ & $1.27 \pm 0.05$ & gram \\
Heart & $160 \pm 4$ & $174 \pm 10$ & $\mathrm{mg}$ \\
Liver \% BW & $6.1 \pm 0.2$ & $5.8 \pm 0.2$ & $\%$ \\
iWAT \% BW & $10.6 \pm 0.3$ & $9.8 \pm 0.3$ & $\%$ \\
gWAT \% BW & $4.2 \pm 0.2$ & $3.9 \pm 0.2$ & $\%$ \\
Heart \% BW & $0.23 \pm .004$ & $0.26 \pm .004$ & $\%$ \\
Triglycerides & $247 \pm 30$ & $309 \pm 22$ & $\mathrm{mg} / \mathrm{dl}$ \\
Free fatty acids & $0.85 \pm 0.10$ & $0.91 \pm 0.09$ & $\mathrm{mEq} / \mathrm{L}$ \\
Cholesterol & $269 \pm 14$ & $301 \pm 8$ & $\mathrm{mg} / \mathrm{dl}$ \\
Glycogen & $81 \pm 8$ & $167.22 \pm 21^{* *}$ & $\mu \mathrm{mol} / \mathrm{g}$ \\
\hline
\end{tabular}

Results are expressed as means $\pm \mathrm{SE}$ (control $\mathrm{n}=6, \mathrm{rFGF} 1 \mathrm{n}=8$ ); * $\mathrm{P}<0.05$, ** $\mathrm{P}<0.01$

\section{Acknowledgments}

We thank L. Chong, J. Alvarez, S. Kaufman, B. Collins, X. Zhao, S. Liu, A. Jurdzinski, A. Bleeker, K. Bijsterveld, Dayoung Oh, and Gautam Bandyopadhyay for technical, and L. Ong and C. Brondos for administrative assistance. Computed Tomography was performed at the Veterans Medical Research Foundation. R.M.E. is a HHMI Investigator at the Salk Institute and March of Dimes Chair, and is supported by NIH grants (DK057978, DK090962, HL088093, HL105278 and ES010337), the Glenn Foundation for Medical Research, the Leona M. and Harry B. Helmsley Charitable Trust, Ipsen/Biomeasure, CIRM, and The Ellison Medical Foundation. C.L. and M.D. are funded by NHMRC (grants 512354, 632886 and 1043199); J.W.J. by ERC grant (IRG-277169), HFSP (CDA00013/2011-C), the NOSR (VIDI grant 016.126.338), the Dutch Digestive Foundation (grant WO 11-67) and the Dutch Diabetes Foundation (grant 2012.00.1537); J.M.O. by NIH grants (DK-033651, DK-074868, T32DK-007494, DK-063491, and P01-DK054441-14A1) and the Eunice Kennedy Shriver NICH and Human Development/NIH through cooperative agreement of U54-HD-012303-25 as part of the specialized Cooperative Centers Program in Reproduction and Infertility Research; and M.A. by an F32 Ruth L. Kirschstein National Research Service Award (NIDDK).

\section{References and Notes}

1. Beenken A, Mohammadi M. The FGF family: biology, pathophysiology and therapy. Nat Rev Drug Discov. 2009; 8:235-253. [PubMed: 19247306]

2. Itoh N, Ornitz DM. Fibroblast growth factors: from molecular evolution to roles in development, metabolism and disease. J Biochem. 2011; 149:121-130. [PubMed: 20940169] 
3. Jonker JW, et al. A PPARgamma-FGF1 axis is required for adaptive adipose remodelling and metabolic homeostasis. Nature. 2012; 485:391-394. [PubMed: 22522926]

4. Sun K, Scherer PE. The PPARgamma-FGF1 axis: an unexpected mediator of adipose tissue homeostasis. Cell Res. 2012

5. Lehrke M, Lazar MA. The many faces of PPARgamma. Cell. 2005; 123:993-999. [PubMed: 16360030]

6. Kharitonenkov A, et al. FGF-21 as a novel metabolic regulator. J Clin Invest. 2005; 115:1627-1635. [PubMed: 15902306]

7. Dutchak PA, et al. Fibroblast growth factor-21 regulates PPARgamma activity and the antidiabetic actions of thiazolidinediones. Cell. 2012; 148:556-567. [PubMed: 22304921]

8. Zinn KR, et al. Imaging Tc-99m-labeled FGF-1 targeting in rats. Nucl Med Biol. 2000; 27:407-414. [PubMed: 10938477]

9. Lee J, Blaber M. The interaction between thermodynamic stability and buried free cysteines in regulating the functional half-life of fibroblast growth factor-1. J Mol Biol. 2009; 393:113-127. [PubMed: 19695265]

10. Wu AL, et al. Amelioration of type 2 diabetes by antibody-mediated activation of fibroblast growth factor receptor 1. Sci Transl Med. 2011; 3:113ra126.

11. Li AJ, Tsuboyama H, Komi A, Ikekita M, Imamura T. Strong suppression of feeding by a peptide containing both the nuclear localization sequence of fibroblast growth factor- 1 and a cell membrane-permeable sequence. Neurosci Lett. 1998; 255:41-44. [PubMed: 9839722]

12. Suzuki S, et al. Feeding suppression by fibroblast growth factor-1 is accompanied by selective induction of heat shock protein 27 in hypothalamic astrocytes. Eur J Neurosci. 2001; 13:2299 2308. [PubMed: 11454034]

13. Sasaki K, et al. Effects of fibroblast growth factors and related peptides on food intake by rats. Physiol Behav. 1994; 56:211-218. [PubMed: 7524109]

14. Wei W, et al. Fibroblast growth factor 21 promotes bone loss by potentiating the effects of peroxisome proliferator-activated receptor gamma. Proc Natl Acad Sci U S A. 2012; 109:31433148. [PubMed: 22315431]

15. Holland WL, et al. An FGF21-adiponectin-ceramide axis controls energy expenditure and insulin action in mice. Cell Metab. 2013; 17:790-797. [PubMed: 23663742]

16. Lin Z, et al. Adiponectin mediates the metabolic effects of FGF21 on glucose homeostasis and insulin sensitivity in mice. Cell Metab. 2013; 17:779-789. [PubMed: 23663741]

17. Hevener AL, et al. Muscle-specific Pparg deletion causes insulin resistance. Nat Med. 2003; 9:1491-1497. [PubMed: 14625542]

18. Van Dijk TH, Boer TS, Havinga R, Stellaard F, Kuipers F, Reijngoud DJ. Quantification of hepatic carbohydrate metabolism in conscious mice using serial blood and urine spots. Anal Biochem. 2003; 322:1-13. [PubMed: 14705774] 

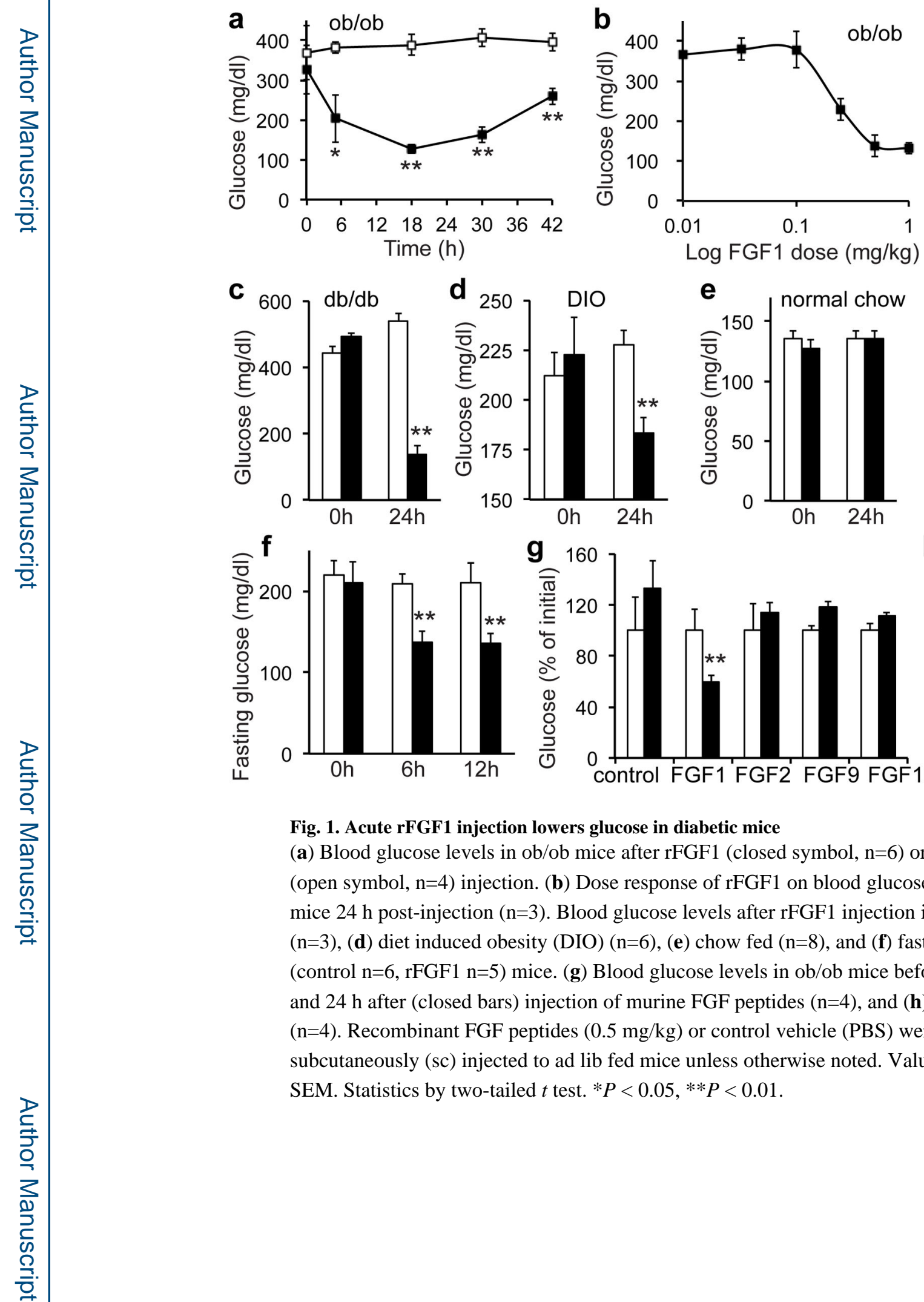

Fig. 1. Acute rFGF1 injection lowers glucose in diabetic mice

(a) Blood glucose levels in ob/ob mice after rFGF1 (closed symbol, n=6) or control vehicle (open symbol, $n=4$ ) injection. (b) Dose response of rFGF1 on blood glucose levels in ob/ob mice 24 h post-injection ( $n=3)$. Blood glucose levels after rFGF1 injection in (c) db/db $(n=3),(\mathbf{d})$ diet induced obesity (DIO) $(n=6),(\mathbf{e})$ chow fed $(n=8)$, and $(\mathbf{f})$ fasted ob/ob (control $\mathrm{n}=6$, rFGF1 $\mathrm{n}=5$ ) mice. (g) Blood glucose levels in ob/ob mice before (open bars) and $24 \mathrm{~h}$ after (closed bars) injection of murine FGF peptides $(\mathrm{n}=4)$, and (h) human rFGF1 $(\mathrm{n}=4)$. Recombinant FGF peptides $(0.5 \mathrm{mg} / \mathrm{kg})$ or control vehicle (PBS) were subcutaneously ( $\mathrm{sc}$ ) injected to ad lib fed mice unless otherwise noted. Values are means \pm SEM. Statistics by two-tailed $t$ test. $* P<0.05, * * P<0.01$. 

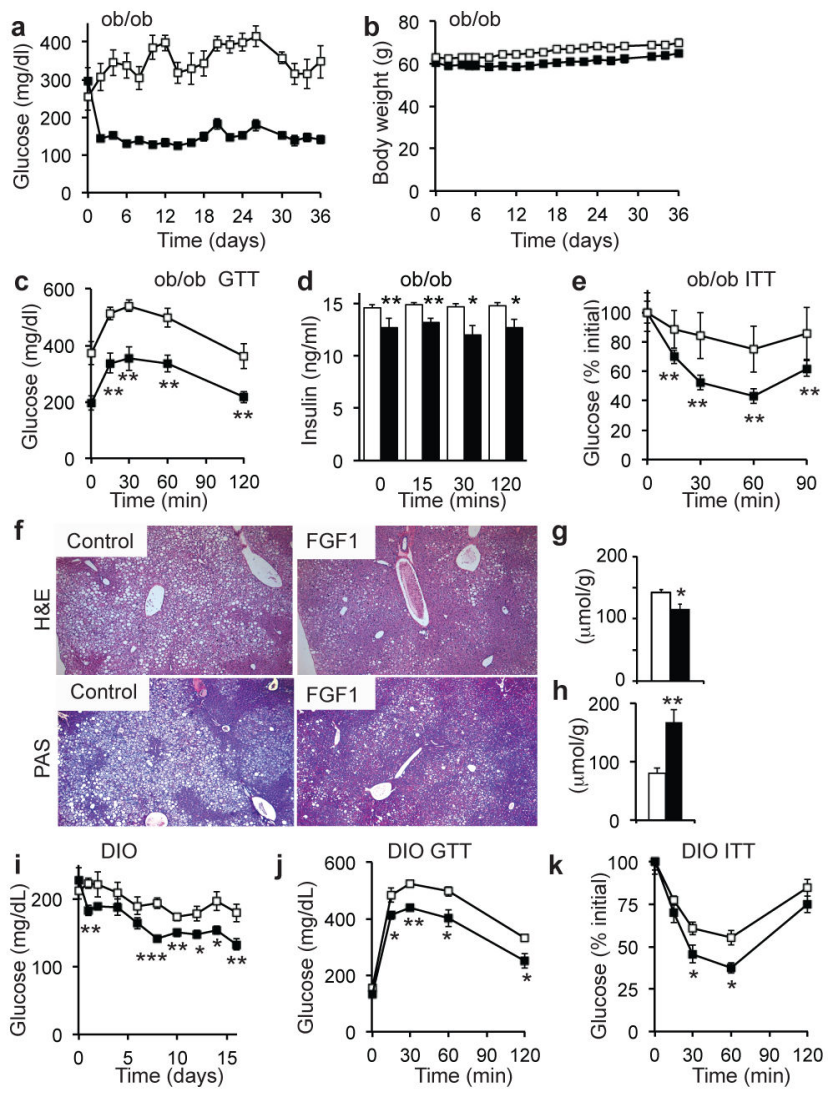

Fig. 2. Chronic rFGF1 administration achieves sustained glucose lowering and insulin sensitization in diabetic mice

(a) Random fed blood glucose and (b) body weight during chronic rFGF1 treatment. (c) glucose tolerance test (GTT), (d) insulin levels during GTT, and (e) insulin tolerance test (ITT) measured in ob/ob mice after 4 weeks rFGF1 treatment (control $n=6, r F G F 1 n=8$ ). (f) Representative hematoxylin and eosin (H\&E) and periodic acid-schiff staining (PAS, magenta represents glycogen), (g) triglyceride, and (h) glycogen content of ob/ob livers after 5 weeks chronic rFGF1 treatment (overnight fasted, control $n=6, r F G F 1 n=8$ ). (i) Random fed blood glucose, (j) GTT and (k) ITT in DIO mice after 3 weeks rFGF1 treatment $(n=6)$. Ad lib fed mice were injected sc with $0.5 \mathrm{mg} / \mathrm{kg}$ rFGF1 (filled bars) or control vehicle (PBS open bars) every $48 \mathrm{hrs}$. Values are means \pm SEM. Statistics by two-tailed $t$ test. $* P<0.05$, $* * P<0.01, * * * P<0.005$ 

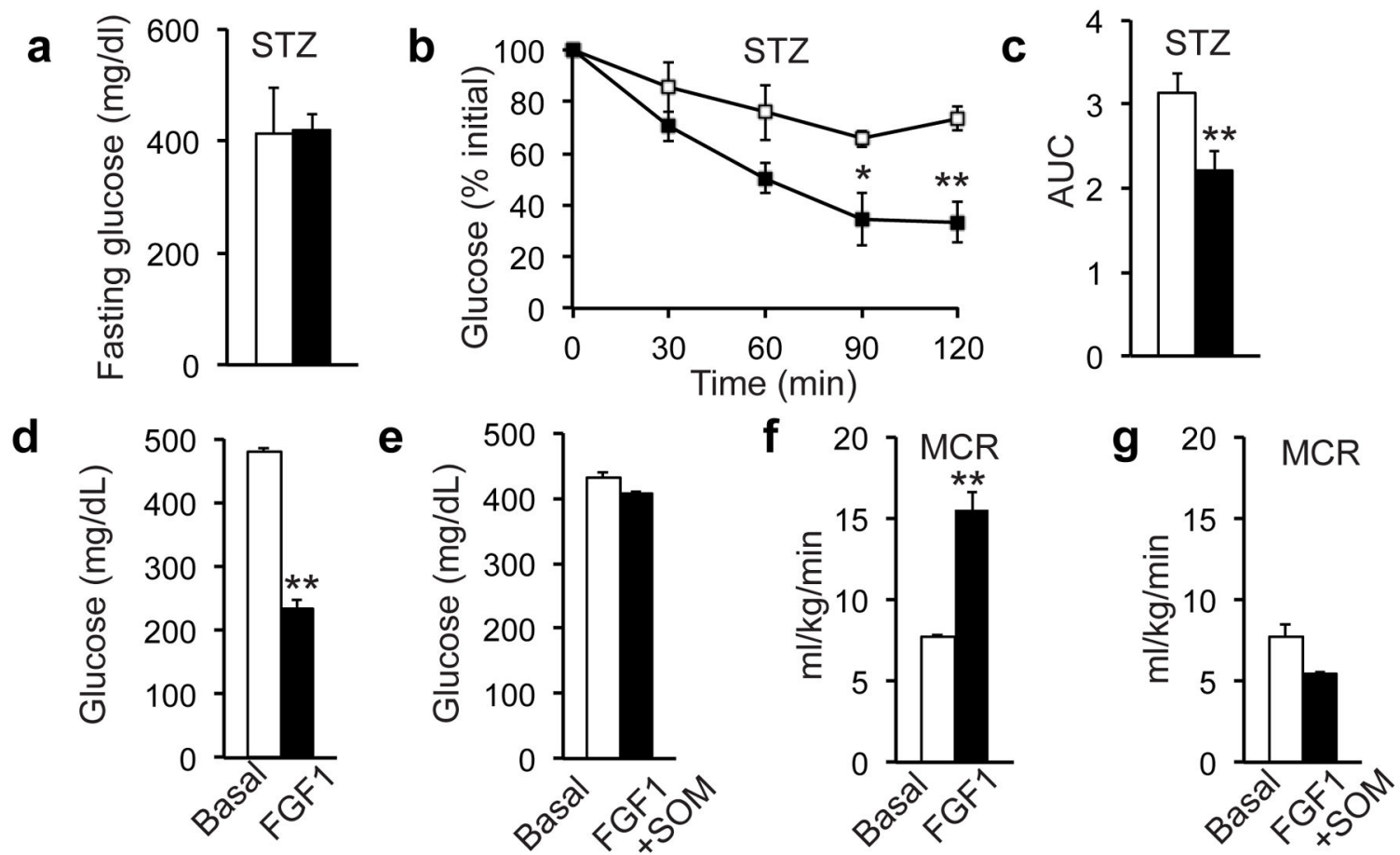

Fig. 3. rFGF1 induces insulin-dependent glucose uptake

(a) Blood glucose levels in STZ-induced diabetic mice $8 \mathrm{hrs}$ after sc injection of control PBS (open bars) or rFGF1 (0.5 mg/kg, filled bars). (b) ITT and (c) area under the ITT curve of control- and rFGF1-treated STZ mice (open and closed symbols, respectively, $n=4$ ). Ob/ob blood glucose level and metabolic clearance rate (MCR) after control PBS (open bar) or rFGF1 injection $(0.2 \mathrm{mg} / \mathrm{kg}$ iv, filled bar) before $(\mathbf{d}, \mathbf{f})$ or $1 \mathrm{hr}$ after $(\mathbf{e}, \mathbf{g})$ somatostatin infusion $(\mathrm{n}=5)$. Values are means $\pm \mathrm{SD}$. Statistics by two-tailed $t$ test. $* P<0.05, * * P<0.01$ 

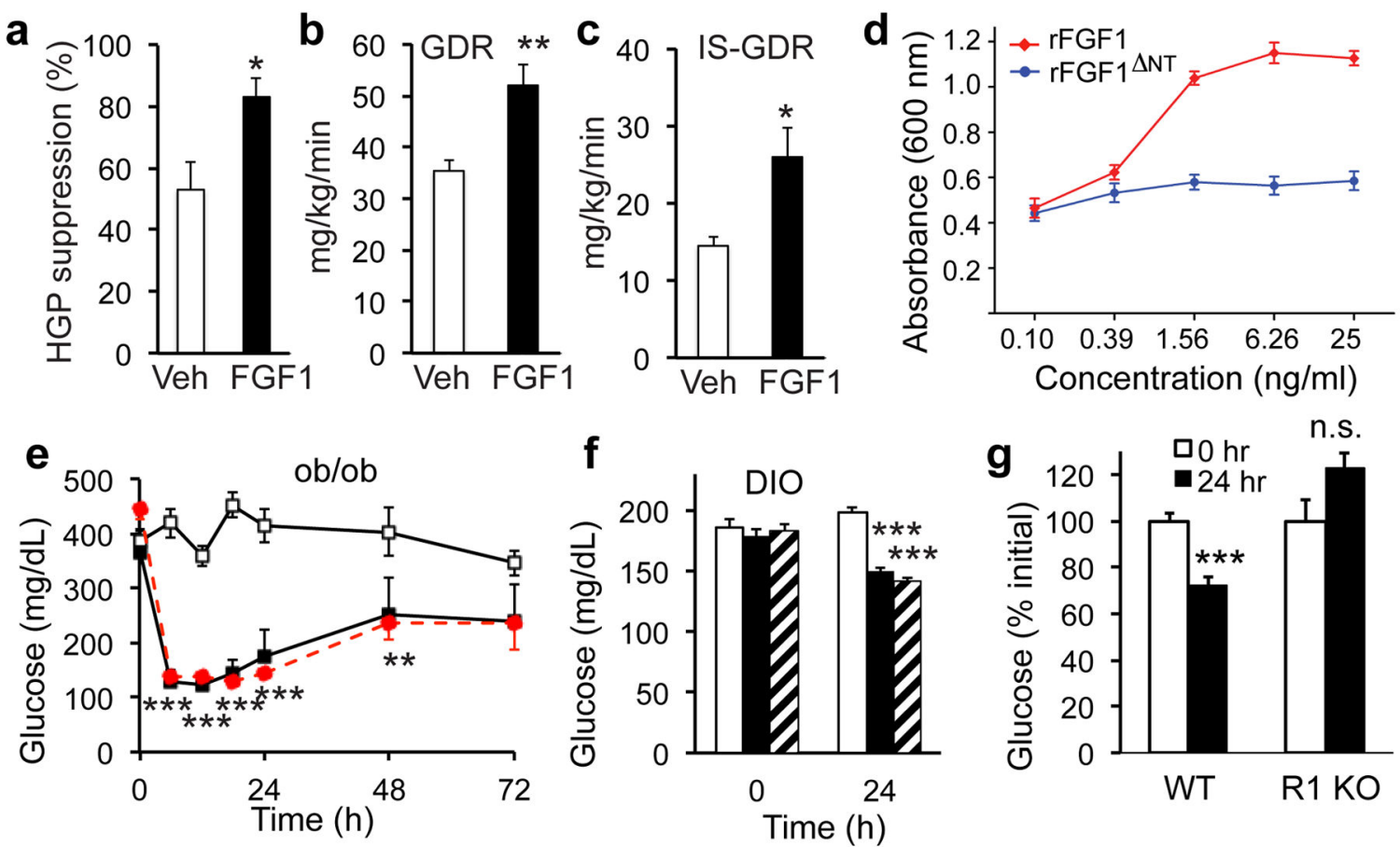

Fig. 4. Chronic rFGF1 administration is insulin sensitizing

(a) Insulin-stimulated hepatic glucose suppression, (b) steady state glucose disposal rate (GDR), and (c) insulin-stimulated glucose disposal rate (IS-GDR) measured during hyperinsulinemic-euglycemic clamps on DIO mice after 3 weeks control PBS (open bars $\mathrm{n}=11)$ or $\mathrm{rFGF} 1(0.5 \mathrm{mg} / \mathrm{kg}$ sc q.a.d., closed bars $\mathrm{n}=9)$ treatment. (d) Proliferative activity of NIH3T3 cells treated with $\mathrm{rFGF} 1$ or $\mathrm{rFGF} 1^{\Delta \mathrm{NT}}$ at the indicated concentrations (experiment repeated 3 times). (e) Blood glucose levels of ob/ob mice treated with control PBS (open symbols $\mathrm{n}=12), \mathrm{rFGF} 1(0.5 \mathrm{mg} / \mathrm{kg}$ sc, filled symbols, $\mathrm{n}=8)$, or $\mathrm{rFGF} 1^{\Delta \mathrm{NT}}(0.5 \mathrm{mg} / \mathrm{kg} \mathrm{sc}$, dashed line, $n=6$ ). (f) Blood glucose levels of DIO mice treated with control PBS (open bars), $\mathrm{rFGF} 1$ (0.5 mg/kg sc, filled bars), or $\mathrm{FFGF}^{\Delta \mathrm{NT}}(0.5 \mathrm{mg} / \mathrm{kg}$ sc, striped bars $)$ at indicated times ( $\mathrm{n}=10)$. (g) Blood glucose levels in high-fat diet fed (8 months) $\mathrm{Fgfrl} \mathrm{fl/fl}$ (WT, n=5) and aP2-Cre; $F g f r l \mathrm{fl} / \mathrm{fl}(\mathrm{R} 1 \mathrm{KO}, \mathrm{n}=4)$ mice at 0 (open bars) and $24 \mathrm{hrs}$ (filled bars) after $\mathrm{rFGF} 1$ treatment $(0.5 \mathrm{mg} / \mathrm{kg} \mathrm{sc})$. Values are means $\pm \mathrm{SEM}$. Statistics by twotailed $t$ test. $* P<0.05, * * P<0.01, * * * P<0.005$ 